\title{
Overcoming Communication Breakdowns through the Use of Communication Strategies: Perceptions, Practices and Perspectives
}

\author{
Melouka Ziani \\ university Abdelhamid Ibn Badis, Mostaganem
}

\begin{abstract}
Verbal communication is the most deterrminant aspect of communicative competence among foreign language speakers .In EFL classrooms, the foreign language learner ,frustratedly experiences misunderstanding or even a communication gap with his teacher or class mates. The present paper, then, tries partly to investigate the causes behind communication breakdowns in EFL classes and the strategies used by our learners to overcome their limitations in verbal communication. The data obtained through the combination of two tools revealed that our learners are not aware of the strategies that help them get rid of such deficiencies. Hence, the role of the teacher in training his learners to use indirect strategies (Oxford, 1990), mainly compensation ones that help them overcome communication breakdowns.
\end{abstract}

Keywords : Communication breakdowns- indirect strategies-compensation strategies 